\title{
A new cavernicolous and eyeless species of the genus Lymnastis from Christmas Island, Australia (Insecta: Coleoptera: Carabidae: Bembidiinae)
}

\author{
Martin Baehr \\ Zoologische Staatssammlung, Münchhausenstr. 21, D-81247 München, Germany \\ Email: martin.baehr(a'zsm.mwn.de
}

\begin{abstract}
Lymnastis brooksi sp. nov, is described from a cave on Christmas Island in the northern Indian Ocean. The sole specimen is depigmented and completely eyeless, and moreover is easily distinguished from other species of the genus Lymnastis Motschulsky by the large pronotum bearing remarkably acute and projected basal angles, by the almost non-serrate margins of the elytra, and by their very inconspicuous striation. The relationships of the new species so far are unsettled. A preliminary key to the species of Lymnastis recorded from the Oriental, Papuan and Australian regions is provided.
\end{abstract}

Keywords: taxonomy, new species, Christmas Island, Lymnastis

\section{INTRODUCTION}

The carabid beetle genus Lymnastis Motschulsky is characterized mainly by the sparsely pilose surface, the usually depressed body, the depigmented or lightly pigmented colouration, and the absence or rudimentary development of the apical striole on the elytra. It is closely related to the American genus Micratopus Casey from which it differs mainly in some features of the mouth parts.

At present the genus comprises about 40 species (Lorenz 2005), which are distributed through the Eastern Hemisphere, from Mediterranean Europe including the Atlantic islands, through Africa, southern mainland and insular Asia, New Guinea, New Britain, and Australia, with one species each occurring in Central America and on Hawaii, respectively. Most species of the genus are quite similar in shape and appearance, being large-eyed and capable of flight, but some species from Europe, Africa, and New Guinea are eyeless and usually also short-winged.

The fully winged species generally occur in more or less damp places and are most commonly encountered at light, whereas the eyeless species usually are found under deeply imbedded stones or in earth cracks (Jeannel 1932; Andrewes 1935; Darlington 1962), those occurring on the Canary lslands also were recorded from volcanic caves (Machado 1992).

Apparently, females are more commonly sampled than males (Jeannel 1932; personal observations on Australian Lymnastis), but this may be due to the sampling techniques employed, because females may more easily come to light than males.

Through courtesy of Bill Humphreys of Western
Australian Museum, I received an unidentified bembidine specimen collected in a cave on Christmas Island in the Indian Ocean, for identification. Examination of the specimen revealed that it belongs to the genus Lymnastis and represents a remarkable, undescribed species.

\section{MATERIALS AND METHODS}

Whereas the new cavernicolous specimen was loaned from Western Australian Museum, Perth (WAM), material for comparison of the Oriental species $L$. atricapillus Bates, $L$. coomani Jeannel, and L. pilosus Bates was taken from my working collection.

For the description current methods were used. In view of the small size of the specimen, drawing of the habitus was preferred because this seems more favourable than taking photographs.

The specimens were examined using a bifocal Leitz Stereo Microscope with up to $160 x$ magnification. I used one or even two very bright Wild lamps that can be focused.

Measurements were taken using a stereo microscope with an ocular micrometer. Length was measured from the apex of the labrum to the apex of the elytra. Body lengths, therefore, may slightly differ from those specified by other authors. The length of the pronotum was measured from the most advanced part of the apex to the most advanced part of the base. The width of the apex of the pronotum was measured between the most advanced parts of the apical angles, and the width of the base at the widest part of the basal angles. The length of the elytra was measured from the 
most advanced part of the humerus to the very apex.

\section{SYSTEMATICS}

\section{Family Carabidae}

\section{Subfamily Bembidiinae}

\section{Genus Lymnastis Motschulsky, 1862}

Lymnastis Motschulsky, 1862: 27; Csiki 1928: 170 Jeannel 1932: 170; Andrewes 1935: 302; Darlington 1968: 484; Moore et al. 1987: 145; Machado 1992: 188; Lorenz 1998: 195.

\section{Type species}

Lymnaeum indicum Motschulsky, 1851, by monotypy.

\section{Remarks}

Jeannel (1932) provided an extensive diagnosis and a key to the then known species of Lymnastis. The New Guinean species which cover also those recorded from Australia were keyed by Darlington (1962), the known Oriental ones were keyed by Andrewes (1935) and in parts mentioned by Stork (1986).

It should be mentioned, however, that the socalled "Lymnastis pilosus" recorded from Australia and New Guinea not only differ from those occurring in mainland Asia (e.g. Burma and Thailand), but apparently include a number of taxa which differ inter se not only in the shape of the pronotum and elytra and in the size of eyes, but also in features of their male genitalia. This complex at present is being examined.

\section{Lymnastis brooksi, sp. nov.}

Figures 1, 2

\section{Material examined}

\section{Holotype}

Australia: Christmas Island: $q$, Jane Up Cave, cave CI-6, 10²9'20"S, 105³8'36"E (GPS reading), 24 May 2006, R.D. Brooks et al. (BES: 14048) (WAM70301).

\section{Diagnosis}

Lymnastis brooksi is a species of the genus Lymnastis, characterized from all other species by the total absence of eyes, the depigmented, very pale yellow colouration, the large, voluminous pronotum bearing remarkably acute basal angles which conspicuously protrude laterad and posteriad, elongate, almost parallel, barely striate elytra which are not serrulate behind humerus, and the rather glossy, comparatively weakly microreticulate surface.

\section{Description}

Female

Measurements: length $2.3 \mathrm{~mm}$; width $0.78 \mathrm{~mm}$. Width/length of pronotum 1.10; width base/apex of pronotum 1.18; width pronotum/head 1.68; length/ width of elytra 1.79 .

Colour: upper and lower surfaces, and palpi, antennae, and legs very pale yellow.

Head: moderately wide, frons in middle gently and evenly convex, laterally behind clypeal suture with a shallow, slightly oblong impression. Eyes completely absent, not even any traces of ocelli visible. Two supraorbital setae present, the anterior one being shorter. Clypeus markedly hexagonal, bisetose, clypeal suture distinct though not impressed. Frons with an elongate seta on either side just behind clypeal suture. Labrum with apex slightly concave, quadrisetose. Mandibles short and compact, with high scrobe and with a quite elongate seta within scrobe. Mentum with an obtusely triangular tooth, bisetose besides tooth. Submentum quadrisetose. Glossa narrow and elongate, bisetose at apex, paraglossae hyaline, very slightly surpassing glossa. Lacinia elongate, inner margin

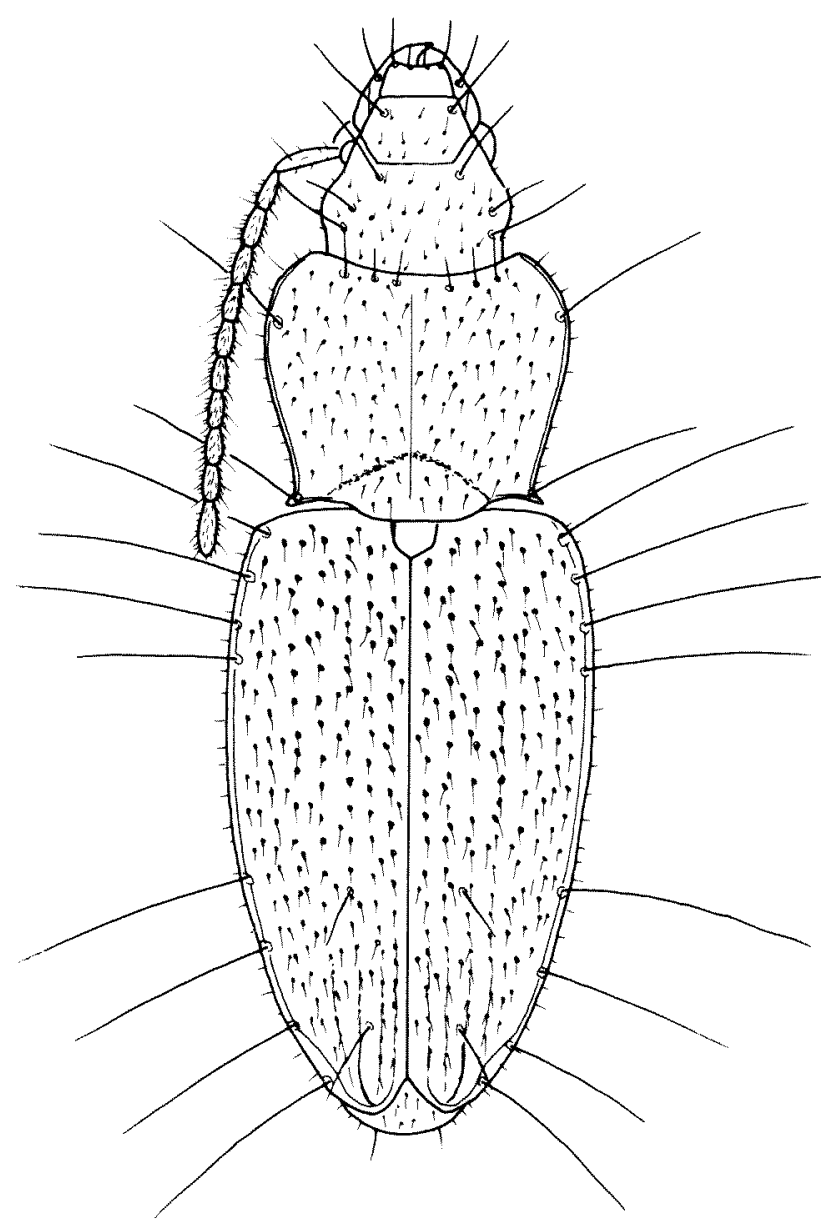

Figure 1 Lymnastis brooksi sp. nov., holotype female, habitus. Length $2.3 \mathrm{~mm}$. 
strongly spinose. Labial palpus small, penultimate palpomere globose, sparsely setose, terminal palpomere subulate, elongate. Maxillary palpus large, penultimate palpomere moderately globose, rather sparsely setose and with a ring of short setae at apex, terminal palpomere very short. Antenna comparatively elongate (in group), median antennomeres even slightly longer than wide, antennomeres completely pilose. Surface of head with very sparse, rather coarse punctures, with sparse, erect or slightly inclined, comparatively short pilosity, and with distinct though superficial, about isodiametric microreticulation, surface quite glossy. Also the eye area sparsely and shortly pilose.

Pronotum: in comparison to other species of the genus very large and elongate, voluminous, dorsally rather convex, lateral margins evenly convex, only very shortly but rather deeply sinuate immediately in front of the basal angles. Widest diameter very slightly in front of middle. Apical angles rounded, barely produced, apex gently concave, not margined. Lateral margin narrow, marginal sulcus shallow though distinct. Basal angles very acute, markedly projected laterad and slightly posteriad. Base in middle produced, laterally excised and from excision to basal angle narrowly margined. No anterior transverse sulcus visible, median line perceptible but not impressed, basal sulcus about triagonal, in middle barely impressed. Basal grooves barely indicated. Anterior lateral seta situated slightly in front of middle, posterior lateral seta situated at a very short distance in front of basal angle, both setae very elongate. Apical margin with a transverse row of six fairly elongate, erect setae. Dorsal surface with sparse, rather coarse punctures, with sparse, partly erect but on disk rather inclined, remarkably short pilosity, and with very superficial, slightly transversal microreticulation; surface very glossy.

Elytra: comparatively elongate, dorsally gently convex, in basal third almost parallel, then gently and evenly rounded to the obtusely-convex apical angles, widest diameter close to base. Humeri very slightly obtuse, almost rounded. Lateral margin behind humerus not perceptibly serrulate. Apex

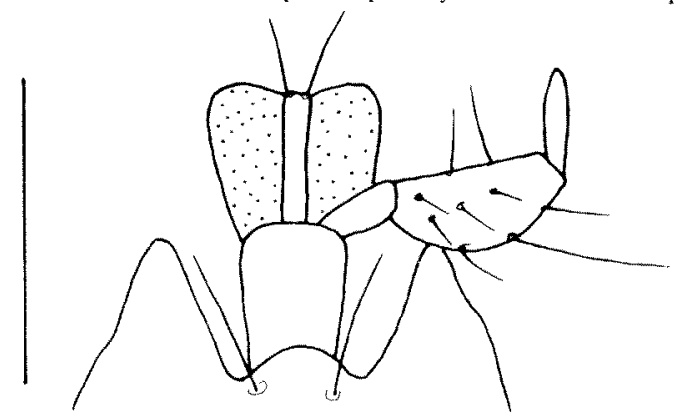

Figure 2 Lymnastis brooksi, sp. now, holotype female: mentum and labium, ventral view. Scale: 0.1 $\mathrm{n} \mathrm{m}$. deeply dehiscent. Striae in basal halt almost not perceptible, towards apex slightly more distinct, but not at all impressed. Intervals absolutely depressed, with uniseriate to irregularly biseriate punctuation of fairly coarse punctures which give the intervals the appearance of bearing faint, irregular, transverse strioles. Intervals with comparatively short, erect pilosity. Also the lateral margin sparsely and shortly pilose. Apical striole short and very indistinct. Surface with isodiametric to very slightly transverse, superficial microreticulation, therefore surface comparatively glossy. Margin with 4 anterior and 4 posterior marginal punctures and very elongate setae, separated by a wide space in middle, but punctures difficult to detect when setae broken. $3^{\text {rd }}$ interval with two discal punctures and rather elongate, erect setae, the anterior puncture situated at apical third, the posterior one situated near apex. The posterior seta longer than the anterior one.

Posterior wings: very much reduced.

Lower surface: proepisternum and prosternum with superficial, transverse microreticulation, abdomen with very elongate, transverse lines, whole lower surface glossy, sparsely pilose, pilosity short, erect. Also the lateral margins of abdomen shortly pilose. Metepisternum slightly longer than wide at apex, but partly concealed by the epipleurae. Female with two elongate setae at apex of terminal sternite.

Legs: of average size and shape.

Female stylomeres: Not dissected to preserve the unique specimen.

\section{Distribution}

This species is only known from the type locality on Christmas Island, northern Indian Ocean.

\section{Remarks}

The biology of this species is unknown, although some information about the collecting circumstances is available thanks to the kindness of Julianne Waldock. The type locality is a very humid freshwater stream cave about $137 \mathrm{~m}$ long and 15.5 $m$ deep on the top of Christmas Island which is a calcareous island. The holotype was collected under leaf litter which was placed two weeks before on a damp, muddy soil bank near the end of the cave which is in total darkness.

\section{Relationships}

This is an unique species which in its external morphological characters is very different from all recorded species in the nearer vicinity.

\section{Etymology}

The name is a patronym and honours one of the collectors of this species, Darren Brooks. 


\section{Remarks}

The small, isolated seamount of Christmas Island lies in the northern Indian Ocean, only about 150 $\mathrm{km}$ south of Java. The surface is largely calcareous and bears several caves which have been intensively studied. An interesting cave fauna has been recorded, including a blind scorpion, stygobitic shrimps (see Humphreys and Eberhard 2001 for additional information on the cavernicolous fauna), and also another tiny carabid of the anilline lineage which is presently studied by P. M. Giachino.

Lymnastis brooksi is the second eyeless species of the bembidiine genus Lymnastis recorded from the southern Oriental and Australian-Papuan regions but is the only species within this area that has been collected from within a cave. The other species, Lymnastis inops Darlington from Papua New Guinea, was found at rather high altitude (between about 1,800 and $2,500 \mathrm{~m}$ ), from under a deeply imbedded stone in limestone country. Certainly, however, cavernicolous habits of the New Guinean species cannot be denied, because transition from geophilous to cavernicolous habits is common in many other blind bembidiine and trechine species living in calcareous environments.

As the Christmas Island specimen was caught under leaf litter introduced into the cave by the collectors, it is not possible to decide whether the species normally lives free running on the ground or concealed in earth cracks or within the soil.

All other Lymnastis species from Australasia are large-eyed beetles capable of flight which probably live in ground litter under more or less wet conditions and which are usually sampled at light by collectors. From mainland Australia only $L$. pilosus Bates has been recorded, and from New Guinea L. atricapillus Bates as well. However, a review in progress of Australian and New Guinean material suggests that several additional forms are involved, though additional material and comparison with the types of earlier described but synonymized species is required unless final taxonomic decisions are possible.

From the adjacent islands Sumatra and Java so far only the widespread species $L$. pilosus has been recorded (Andrewes 1933, 1935), which does not seem to be closely related to $L$. brooksi.

\section{Preliminary key to the species of Lymnastis from South Asia, New Guinea and Australia}

(The Australian and New Guinean forms presently are subject of revisionary work)

1. Eyes absent .................................................. 2

Eyes present, usually large and prominent ..... 3

2. Size larger, total length $>2.7 \mathrm{~mm}$; elytra behind humerus markedly serrate [Papua New Guinea, at high altitude].
Size smaller, total length c. $2.3 \mathrm{~mm}$; elytra behind humerus not perceptibly serrate [Christmas Island, northern Indian Ocean, in cave] L. brooksi, sp. nov.

3. Surface very coarsely punctate; elytra without microreticulation, glossy [Burma, eastern India] ........................ L. indicus Motschulsky

Surface less coarsely punctate; elytra with distinct microreticulation ... 4

4. Elytral striae very faint, even sutural stria impressed only near apex; microreticulation isodiametric; $3^{\text {rd }}$ interval with a single setiferous puncture; size very small, length $1.7 \mathrm{~mm}$ [eastern India]

L. pullulus Motschulsky

Inner elytral striae distinctly impressed; microreticulation transverse; $3^{\text {rd }}$ interval with two setiferous punctures; size usually larger, length $>1.8 \mathrm{~mm}$ 5 .

5. Prothorax and elytra yellow, head dark piceous to black [Burma, Borneo, Philippines, New Guinea] L. atricapillus Bates

Colour uniformly yellow 6.

6. Elytra narrow and elongate, ratio length/width $>1.84$; pronotum smaller, ratio width/length $<1.20$; body size smaller, total length $<2 \mathrm{~mm}$; aedeagus (seen from right) without a distinct convexity at lower surface [Thailand, Vietnam] ......................... L. coomani Jeannel

Elytra shorter and wider, ratio length/width < 1.75; pronotum larger, ratio width/length $>$ 1.28; body size larger, total length $>2 \mathrm{~mm}$; aedeagus (seen from right) with a distinct convexity at lower surface [South-east Asia from India through the Indonesian and Philippine insular belts to Sulawesi and the Moluccas; the occurrence in New Guinea, New Britain, and Australia is doubtful] ......... L. pilosus Bates

\section{ACKNOWLEDGEMENTS}

I am greatly indebted to Julianne Waldock and Bill Humphreys, of the Western Australian Museum, for the kind loan of the specimen and information about collecting circumstances.

\section{REFERENCES}

Andrewes, H.E. (1933). A catalogue of the Carabidae of Sumatra. Tijdschrift voor Entomologie 76: 318-382.

Andrewes, H.E. (1935). The Fauna of British India, including Ceylon and Burma. Coleoptera. Carabidae. II. Harpalinae I. Taylor \& Francis: London.

Csiki, E. (1928). Carabidae: Mormolycinae, Harpalinae I. Coleopterorum Catalogus II (97): 1-226. W. Junk: Berlin. 
Darlington, P.J., Jr. (1962). The carabid beetles of New Guinea. Part 1. Cicindelinae, Carabinae, Harpalinae through Pterostichini. Bulletin of the Museum of Comparative Zoology 126: 321-565.

Darlington, P.J., Jr. (1968). The carabid beetles of New Guinea. Part III. Harpalinae (Continued): Perigonini to Pseudomorphini. Bulletin of the Museum of Comparative Zoology 137: 1-253.

Humphreys, W.F. and Eberhard, S. (2001). Subterranean fauna of Christmas Island, Indian Ocean. Helictite $37(2): 59-74$.

Jeannel, R. (1932). Revision du genre Lymnastis. Société entomologique du France. Livre du Centenaire, Paris: 167-187.

Lorenz, W. (1998). Systematic List of extant Ground Beetles of the World (Insecta Coleoptera "Geadephaga": Trachypachidae and Carabidae incl. Paussinae, Cicindelinae. Rhysodidae). Printed by the author: Tutzing.

Lorenz, W. (2005). Systematic List of extant Ground Beetles of the World (Insecta Coleoptera "Geadephaga": Trachypachidae and Carabidae incl. Paussinae, Cicindelinae. Rhvsodidae), 2nd edition. Printed by the author: Tutzing.
Machado, A. (1992). Monografia de los Carábidos de las Islas Canarias (Insecta, Coleoptera). Instituto de Estudios Canarios: La Laguna.

Moore, B.P., Weir, T.A. and Pyke, J.E. (1987). Rhysodidae and Carabidae. In: Zoological Catalogue of Australia, vol. 4: 17-320. Australian Government Publishing Service: Canberra.

Motschulsky, V. (1851). Enumération des nouvelles especes de coléopteres rapportés par M. Victor Motschoulsky de son dernier voyage. Bulletin de la Société Impériale des Naturalistes de Moscou 24(2): 479-511.

Motschulsky, V. (1862). Entomologie spéciale. Remarques sur la collection d'insectes de V. de Motschulsky. Coléoptères. Études entomologique 11: 15-55.

Stork, N.E. (1986). An annotated checklist of the Carabidae (including Cicindelinae, Rhysodinae and Paussinae) recorded from Borneo. Occasional Papers on Systematic Entomology 2: 1-24.

Manuscript accepted 2 October 2007 